\title{
LA HISTORIA CONTEMPORÁNEA DE MÉXICO Y LA HISTORIA GLOBAL: REFLEXIONES ACERCA DE LOS “SESENTA GLOBALES”
}

\author{
Stephan Scheuzger \\ Universität Bern
}

"Гodo es culpa de la minifalda". ${ }^{1}$ Así resumió Leopoldo 1 García Trejo, empleado de Correos, lo que advirtió y entendió del movimiento estudiantil de 1968 en México. En su absurdo reduccionismo, el comentario revela, paradójicamente, mucho más sobre la complejidad del hecho histórico de lo que parece. En 1968 se relacionaron procesos locales en el ámbito global para producir similitudes y diferencias en el desafío de órdenes políticos y sociales establecidos. La simultaneidad de estos fenómenos se debía, obviamente, no sólo a coincidencias y condiciones compartidas, sino también a la circulación de información, ideas y símbolos a través de fronteras nacionales y espacios culturales - lo que también sentaba las bases para la construcción del "68" como hecho histórico. Y lo que circulaba entre San Francisco, París, la ciudad de México, Tokio o El Cairo, como en un sinnúmero de otros lugares alrededor del mundo

Fecha de recepción: 28 de febrero de 2017

Fecha de aceptación: 23 de agosto de 2017

${ }_{1}^{1}$ Poniatowska, La noche de Tlatelolco, p. 86. 
- en la mayoría urbanos, pero también rurales -, eran mucho menos proyectos políticos anticapitalistas y antiimperialistas definidos que narraciones, imágenes y estilos de vida. Todo esto, García Trejo lo puso de relieve, así como el hecho de que no sólo los que cuestionaban a las autoridades y los valores dominantes participaban en esta circulación, sino también aquellos que veían cuestionados su autoridad o sus valores: su comentario hizo eco de una denuncia hecha desde las instancias del poder político y de la prensa aliada a éste y que desembocaba en una represión cuyo objetivo eran asimismo mujeres con minifaldas y hombres con pelo largo. Lo político y lo cultural se entretejían tanto en los desafíos anti-establishment como en las reacciones del establishment a ellos. En todos los lugares alrededor del mundo esto sucedió en constelaciones de interacciones transnacionales.

Tanto la relación con sucesos en otros lugares del planeta como la interdependencia de política y cultura forman parte de los conocimientos básicos sobre el “68” no sólo en México. Mucho se ha escrito sobre este año clave en la historia contemporánea, que se sitúa en el contexto mexicano como cesura en la "historia postrevolucionaria” y que en la historia internacional marca un hito en lo que suele abordarse como la "historia de la posguerra". Sin embargo, hay que destacar que a pesar de la abundancia de publicaciones sobre el 68 en México, que abarca también su prehistoria, causas y contextos, sorprende lo poco que se sabe tanto sobre el significado exacto de los entrelazamientos transnacionales para los sucesos en México, como sobre la relación entre la contracultura y la política en el desafío del orden establecido. Esta contribución no tiene como propósito llenar estas lagunas. Como una intervención historiográfica, se pregunta más bien por el potencial que ofrecen las nuevas perspectivas de la historia global para hacer esto. Ampliando la perspectiva sobre el 68 - que se puede calificar en términos políticos y político culturales como el hecho más importante entre el sexenio cardenista con sus reformas estabilizadoras del 
régimen surgido de la revolución mexicana y el fin de este régimen en términos de política partidista - hacia la idea de los global sixties, que experimenta desde hace algunos años un auge en la historiografía internacional, el presente artículo propone una reflexión sobre lo que pueden significar los planteamientos de la historia global para la comprensión de un periodo considerado decisivo para la historia contemporánea mexicana, pero en cierta medida también para la interpretación de fenómenos históricos más allá del marco de las historias nacionales. Este sondeo se hace a la luz del diagnóstico de que la historiografía sobre América Latina, y probablemente todavía más las ciencias históricas en el subcontinente, han quedado hasta ahora al margen de la coyuntura de la historia global.

Desde 1968, dicho año se ha concebido como un acontecimiento global. Muchos de los que participaron en los movimientos asociados al año icónico lo hacían con cierta conciencia de los vínculos que relacionaban sus protestas con las luchas de emancipación en otros lugares alrededor del mundo. Y en México, como en cualquier otra parte, las narraciones de los analistas y de los analizados se han entrelazado íntimamente desde entonces: ${ }^{2}$ hasta en la actualidad, la llamada generación del 68 sigue participando de manera prominente en la interpretación de su historia. Mientras que para los que formaban parte de los movimientos y las protestas, la idea de la globalidad del 68 puede tratarse en las categorías de una "comunidad imaginada", ${ }^{3}$ en el análisis histórico de los hechos no ha quedado muy claro lo que significaba esta condición global. Varios autores han interpretado el año

\footnotetext{
2 Markarian, "Debating Tlatelolco"; Suri, The Global Revolutions of 1968, p. x; FREI, 1968, p. 210.

3 Anderson, Imagined Communities.
} 
como un punto de inflexión a nivel de la historia mundial, algunos respecto a la historia de la Guerra Fría, ${ }^{4}$ otros en cuanto a procesos seculares, como en el caso de Immanuel Wallerstein, quien identificó las “explosiones" de ese año como actos decisivos en la desestabilización de los fundamentos culturales del sistema-mundo como se había desarrollado desde el siglo Xvi, iniciando la crisis final del sistema. ${ }^{5}$ Por su parte, otros historiadores han argumentado no tanto desde una perspectiva de historia universal, sino poniendo énfasis en la simultaneidad de los acontecimientos del 68 con el enfoque, en primer lugar, en contextos nacionales. Las conexiones entre ellos, sin embargo, se han presupuesto más que analizado.

La integración de las distintas regiones del mundo a la percepción de la coincidencia "global” de las protestas ha variado considerablemente. Mientras que Estados Unidos, Francia y Alemania se han tratado como los centros del desafío del orden establecido, otros espacios han parecido intercambiables y se han considerado como periféricos. A estas periferias pertenecían también países del “primer mundo”. Gran Bretaña es uno de los ejemplos más prominentes, en cuyo caso varios autores han coincidido en que sí participaba de manera importante en la revolución cultural que se condensó en el 68 - alegando, por ejemplo, la “invasión británica”-, pero que le faltó la dimensión política que caracterizó las revueltas en otras partes de Europa y del mundo. ${ }^{6}$ Sin embargo, las periferias de un 68 representado como global han comprendido sobre todo el "segundo" y el "tercer mundo". A 20 años del hecho, de entre todas las publicaciones que abordaron el tema en el ámbito nacional, una serie de publicaciones presentaron

\footnotetext{
${ }^{4}$ Por ejemplo, Suri, Power and Protest; Fink, Gassert y Junker, "Introduction".

5 Por ejemplo, Wallerstein, World-Systems Analysis, pp. 84-85.

6 Righart, "Moderate Versions of the "Global Sixties””, pp. 83-84; Marwick, "Six Novels of the Sixties", p. 565.
} 
las protestas y revueltas de ese año como un acontecimiento mundial. Las dos obras de Robert V. Daniels y de David Caute pueden considerarse representativas de las perspectivas en la historiografía de aquel entonces, dado que en ellas el "segundo mundo" - representado por Checoslovaquia - y el "tercer mundo" - representado por Vietnam - se percibieron más que nada en función de lo que se había observado de ellos en el "primer mundo", lo que dio lugar a la crítica al imperialismo, al capitalismo y al comunismo soviético ortodoxo.? A fines de los años noventa, los enfoques de la historia global empezaron a ganar terreno en la historiografía, y en el trigésimo aniversario del 68 se publicaron libros que declararon de manera más explícita la necesidad de analizarlo como un acontecimiento global. Así, por ejemplo, los editores de la antología 1968: The World Transformed realzaron los múltiples entrelazamientos "among the hundreds of protest movements that sprang up around the world". ${ }^{8}$ Pero, otra vez, Praga y Saigón (o Hué) entraron en la perspectiva solamente en su condición de escenarios de la Guerra Fría. Y entre las 18 contribuciones al volumen había una sola sobre el "tercer mundo" que, además, se había agregado después de la conferencia en la cual se basaba la publicación. ${ }^{9}$ En este artículo, Arif Dirlik cubrió los sucesos en seis países asiáticos, africanos y latinoamericanos apoyándose en unas cuantas obras de la literatura secundaria. El hecho de que México fuera uno de ellos no era fortuito: la masacre de Tlatelolco diez días antes de la inauguración de los Juegos Olímpicos en la capital del país había asegurado al movimiento estudiantil mexicano una atención internacional que se reproduciría de ahí en adelante en la historiografía sobre el 68. Cuando trabajos históricos publicados en Estados Unidos o en Europa sobre las

7 Daniels, Year of the Heroic Guerrilla; Caute, Sixty-Eight.

${ }^{8}$ Fink, Gassert y Junker, "Introduction", p. 1.

9 Dirlik, “The Third World"; Dirlik, "Foreword”, p. vii. 
movilizaciones de los estudiantes en este año han integrado un escenario "tercermundista”, el más aludido ha sido el caso mexicano. En concreto, un tomo editado en Francia que ya en 1988 intentó abordar el tema del 68 estudiantil no sólo en una perspectiva nacional sino también global incluyó, junto con muchas contribuciones sobre aspectos franceses de la historia, artículos sobre Estados Unidos, la República Federal Alemana (RFA), Italia, los Países Bajos - con los provos - España, Suecia y México; el último, redactado por Jacques Lafaye. ${ }^{10}$

A pesar de una idea continua de la globalidad de los hechos de 1968 a lo largo de décadas, la consideración de los procesos en las regiones del mundo designadas, según la terminología de la época, como "tercer mundo", y más adelante como "sur global”, quedó al margen. Asimismo, a 40 años de los sucesos era todavía posible abordar el tema bajo un título como "revuelta de la juventud y protesta global”, dedicándose exclusivamente a contextos estadounidenses, europeos y japoneses - como fue el caso de una de las más leídas monografías en alemán sobre 1968. ${ }^{11}$ Pero aunque su perspectiva no era global, este estudio dejó en claro el carácter construido del 68. Retomando la idea de Detlev Claussen de un "código 68", Norbert Frei, el autor del libro, habló al respecto de una "invención". ${ }^{12}$ Sobre el hecho de que 1968 establece relaciones entre múltiples acontecimientos históricos diferentes al pensarlos juntos en una simultaneidad global, existe desde hace varios años un amplio consenso en las publicaciones sobre la materia. Por lo tanto, es posible hablar hasta de una "ilusión de simultaneidad", como lo hizo el mismo Claussen. ${ }^{13}$ Años antes, Michael Kidron y Ronald Segal ya habían ilustrado esto sin querer. En uno de los mapas de su

10 Dreyfus-Armand y Gervereau (coords.), Mai 68; Lafaye, "L'automne de Mexico".

${ }^{11}$ FREI, 1968.

12 Frei, 1968, p. 211; Claussen, “Chiffre 68”.

13 Claussen, “Chiffre 68”, p. 219. 
The State of the World Atlas, intentaron representar los "major student disruptions" de 1968 a 1969 a nivel mundial..$^{14}$ La gráfica muestra un sinnúmero de lugares en todos los continentes -11 en México - donde se rebelaron estudiantes en estos dos años de una manera que hubo intervención de las fuerzas del Estado. A pesar de que los autores invocaron en su texto acompañante un "sentido de unidad" de los actores, el mapamundi de las movilizaciones estudiantiles sirve menos para documentar la globalidad de un fenómeno histórico que para medir la labor interpretativa necesaria para establecer la idea de una comunidad de una amplia gama de sucesos muy heterogéneos. Comprender todos los pronunciamientos en que participaron jóvenes que cursaban estudios en escuelas superiores en el mismo cuadro histórico requeriría por lo menos una serie de aclaraciones, no sólo sobre el número y las identidades de los actores, sino también sobre las causas, contextos y formas de las protestas, y sobre los objetivos de los movimientos, sus estructuras organizativas, así como sobre sus dinámicas y temporalidades.

\section{GLOBAL SIXTIES}

El concepto global sixties - los sesenta globales-, que ha creado en los últimos años la base para un nuevo campo de investigación historiográfica, tiene una variedad de raíces. ${ }^{15}$ Una de ellas ha representado la comprensión de que los procesos cuyo estudio se ha enfocado en el marco temporal del año emblemático de 1968 tenían una historia considerablemente más larga. En esta dimensión temporal, los global sixties están íntimamente relacionados con los long sixties, concepto establecido por Arthur Marwick en su estudio de la revolución

14 Kidron y Segal, The State of the World Atlas, p. 64.

15 Eric Zolov aludió sobre todo a los estudios de la Guerra Fría y de la nueva izquierda. ZoLov, “Introduction”, pp. 349-351. 
cultural en Europa occidental y Estados Unidos en esta década extendida. ${ }^{16}$ Pero no sólo en el ámbito de la historia cultural, sino también en el de la historia política, la perspectiva se ha ampliado hacia desarrollos más largos. Para el contexto mexicano, Jaime Pensado, por ejemplo, adoptó la noción de los long sixties para estudiar la política estudiantil, basado en el argumento de que había sido la experiencia clave de la revolución cubana la que había dado lugar a una nueva forma de protesta de los estudiantes en México - una perspectiva que se inscribió, por lo menos parcialmente, en aquellas de una serie de trabajos que ya se habían dedicado a reconstruir y analizar la historia de las movilizaciones estudiantiles en el país en espacios temporales más extensos. ${ }^{17}$

La carga simbólica del 68 se basa más que nada en la idea de cesura que se atribuye a esta fecha. Comparable a nivel internacional sólo con 1989-1990, este año sigue pareciendo separar el mundo en que estamos viviendo de una época de posguerra inmediata que ya se concibe como un pasado marcadamente diferente y por lo tanto muy lejano. ${ }^{18}$ Ariel Rodríguez Kuri habló también después de 2000 -y del cambio de gobierno del Partido Revolucionario Institucional al Partido Acción Nacional- y, con razón, de 1968 en México como de "una 'escena primaria' de la cultura política mexicana". ${ }^{19}$ Dedicándose a los orígenes inmediatos de la protesta estudiantil de este año, utilizó la metáfora de una chispa arrojada a una pradera seca por los estudiantes de la escuela particular Isaac Ochoterena y de la Vocacional 5, que se enfrentaron los días 22 y 23 de julio en la Ciudadela, así como por los granaderos, que intervinieron con

\footnotetext{
16 Marwick, The Sixties.

17 Pensado, Rebel Mexico. Véase también Mabry, The Mexican University and the State.

18 SuRI, The Global Revolutions of 1968, p. xii.

19 Rodríguez Kuri, “Los primeros días”, p. 182.
} 
suma violencia para suprimir el conflicto. ${ }^{20}$ Aunque en México las semanas entre el 23 de julio y el 2 de octubre realmente marcan un hecho singular y delimitable que contribuyó de manera decisiva al cambio de la cultura política en el país, el análisis histórico tiene que abrir la perspectiva más allá del momento culminante para llegar a una comprensión adecuada de las transformaciones que tuvieron lugar. Sin embargo, extender el marco temporal de un año a una década obviamente no resuelve el problema de la periodización - tampoco si se adopta la idea de unos long sixties. Mawrick delimitó sus años sesenta entre 1958-1959 y 1973-1974. ${ }^{21}$ Aunque Jeremi Suri lo calificó como uno de los autores que han abordado los años sesenta de manera más explítica como una historia global, ${ }^{22}$ es evidente que sus criterios provinieron más que nada de la observación de espacios europeos y estadounidenses. Por consiguiente, el planteamiento de unos global sixties más globales tiene que agudizar el problema de la periodización hasta su insolubilidad. Protagonistas del concepto han proporcionado sólo preguntas al respecto. $¿$ ¿Comenzaron los sesenta en 1963 con el discurso "I have a dream” de Martin Luther King? ¿O en 1961, con la introducción de la píldora anticonceptiva? ¿Por qué no representaron la revolución cubana en 1959 o la independencia de Ghana en 1957 hechos más adecuados? ¿O acaso inició la década en 1955 en Bandung, o en 1954 en Dien Bien Phu y Argel? ¿Y terminó en 1969, cuando el festival de Woodstock inició la mercantilización de la cultura bippie y cuando la desintegración de los Beatles, la violencia en el concierto de los Rolling Stones en Altamont, y el asesinato de Sharon Tate y sus amigos por miembros de la Manson Family en Beverly Hills pusieron fin a la revolución psicodélica? ¿O más bien en 1973, con la crisis del petróleo y el golpe

20 Rodríguez Kuri, “Los primeros días”, p. 223.

${ }^{21}$ Marwick, The Sixties, p. 7.

22 Suri, The Global Revolutions of 1968, p. xxii. 
militar contra el gobierno de la Unidad Popular en Chile? ¿Qué plausible sería extender la década hasta 1979 y la revolución en Nicaragua?23 "Whose sixties?" es entonces la pregunta..$^{24} \mathrm{~A}$ pesar de que a cualquier esfuerzo de periodización es inherente un cierto grado de arbitrariedad, al asumir una perspectiva global ya no parece posible fijar una cronología compartida, menos si se toma en cuenta la imbricación de lo político y lo cultural en lo que representan los años sesenta.

Ante esta evidencia, los autores que han puesto énfasis en la necesidad de incluir al "tercer mundo" de manera prominente en el análisis de los global sixties han llamado la atención ante el peligro de malinterpretar el periodo y de perder la capacidad de advertir la extensión geográfica de los fenómenos de resistencia al definir los sesenta de manera uniforme y tratar el periodo como una "estructura endurecida" en lugar de un flexible "marco temporal general". ${ }^{25}$ Sin embargo, parece más indicado reconocer en primer lugar que los "sesenta globales" representan una contradicción en sus propios términos - excepto que se refieran al espacio de tiempo de 1961 a 1970, y esto justamente no ha sido el propósito de los que han hecho uso de tal categoría. Los "sesenta" no designan tanto un tiempo como acontecimientos y procesos cuya convivencia o bien se presupone o bien se hace objeto de estudio. El término global sixties tuvo su orígen en una suposición, no en un análisis. Uno de los primeros en utilizar la expresión a fines de la década de 1990 fue el historiador holandés Hans Righart. Lo hizo en un artículo dedicado al estudio de la revolución cultural en Gran Bretaña

\footnotetext{
${ }^{23}$ Todas estas propuestas se han hecho en publicaciones que hacen uso del concepto de global sixties: CHRISTIANSEN y SCARLETT, "Introduction", pp. 3-5; MARwick, The Sixties, p. 7; Rutherford et al., "Introduction", pp. 2-3; Storey, "What, When, and Where are the Sixties?", pp. 16-19.

${ }^{24}$ Abdulhadi, "Whose 1960s?".

${ }^{25}$ Christiansen y SCarlett, "Introduction”, p. 4; Rutherford et al., "Introduction", pp. 2-3.
} 
y los Países Bajos como parte "of what I would like to call the cross-national, or, to exaggerate a little, the global sixties". ${ }^{26}$ Teniendo en cuenta que el contexto en el cual situó sus dos casos de estudio incluía sólo a Estados Unidos, Francia y Alemania, hay que calificar la declaración de Righart sobre unos sesenta globales por lo menos como una extrapolación audaz, si no un eurocentrismo robusto. También en los años siguientes varios estudios se enfocaron más o menos exclusivamente en espacios europeos o del Atlántico norte, cuando declararon abordar la historia de los sesenta en un contexto global o situaron su investigación explícitamente en el marco del concepto de los global sixties. ${ }^{27}$ Consecuentemente, la globalidad de los fenómenos estudiados era sobre todo una mera afirmación. Pasaron años hasta que publicaciones - volúmenes colectivos y números de revistas, más que nada - empezaron a presentar una agenda que tiene como meta una integración mucho más prominente de perspectivas sobre contextos latinoamericanos, africanos y asiáticos a la investigación de los global sixties, reclamando "that a truly global analysis of this decade is impossible without an in-depth and prolonged conversation about the Third World". ${ }^{28}$ No puede haber la menor duda en cuanto a la importancia del postulado. Sin embargo, la adopción de la categoría de los global sixties para los enfoques que se inscriben en esta agenda puede calificarse como producto de una doble confusión: primero, una - frecuente en la historiografía actual -, de lo transnacional con lo global, que se encontró en el origen de la noción de los global sixties con los trabajos de Righart, Marwick, Martin Klimke y otros; y después, la confusión entre una categoría que describe fenómenos históricos y otra que describe enfoques analíticos.

\footnotetext{
${ }^{26}$ Righart, "Moderate Versions of the 'Global Sixties'”, p. 84. Cursivas en el original.

${ }^{27}$ Por ejemplo, Horn, The Spirit of '68; Klimke, The Other Alliance; T. S. Brown, West Germany and the Global Sixties.

${ }^{28}$ Christiansen y SCarlett, "Introduction”, p. 16.
} 
La investigación histórica que se dedica a los global sixties, incluyendo o hasta privilegiando perspectivas sobre lo que la mayoría de las veces se designa "tercer mundo", establece, más que nada, un nuevo marco epistemológico..$^{29}$ Con este marco la globalidad de los fenómenos históricos asociados con los global sixties se transforma de una premisa a un objeto de estudio. Esto quiere decir que apenas está por iniciarse una investigación que en algún momento permitirá decir cuáles de estos fenómenos pueden clasificarse como globales y qué significa. Una verdadera "in-depth and prolonged conversation about the Third World" llevará también a un replanteamiento de los hechos y procesos que se pueden identificar como constitutivos de los sesenta. Pero a pesar del actual auge de trabajos sobre los "sesenta globales", la historiografía todavía se encuentra muy lejos de tales resultados: mientras que se han publicado unos pocos volúmenes colectivos que han reunido contribuciones dedicadas sobre todo al estudio de fenómenos en el marco de las historias nacionales - desde Alemania hasta Zimbabwe,$-{ }^{30}$ son muy pocos los esfuerzos de comparaciones sistemáticas o reconstrucciones y análisis de transferencias a través de grandes distancias y espacios culturales. Por ende, los global sixties representan en este momento, en el mejor de los casos, una categoría heurística. Y los que reivindican bajo esta categoría perspectivas globales sobre los sesenta parecen basarse en conceptos no muy diferenciados de la historia global.

\section{HISTORIA GLOBAL}

No cabe duda de que la historiografía latinoamericanista hasta ahora ha quedado al margen de la historia global. Recientemente,

\footnotetext{
${ }^{29}$ Véase ZoLov, "Introduction", p. 353.

${ }^{30}$ Hayton, "'The Revolution Is Over"”; Creary, "Speaking the Language of Protest”.
} 
Matthew Brown buscó las razones del desencuentro y presentó una serie de argumentos contundentes. ${ }^{31}$ Sin embargo, hay un aspecto clave que no recibió la suficiente atención en sus reflexiones. Es evidente, y Brown dedica unos párrafos a este punto, que el aislamiento de la historia de América Latina no puede atribuirse solamente a un descuido por parte del campo de la historia global - aunque esta negligencia ha sido considerable. Por parte de las ciencias históricas en América Latina los factores antagonistas no se han limitado a la fuerte tradición institucionalizada de la historiografía nacional y a la falta de recursos financieros para realizar proyectos con enfoques de historia global. Hay que hablar también - y esto es igualmente válido para muchos historiadores latinoamericanistas en Europa y Estados Unidos - de prominentes reservas o hasta resistencias hacia la historia global. Así, por ejemplo, persiste entre muchos investigadores de esta disciplina la sospecha de que la historia global a fin de cuentas representa un eurocentrismo renovado que impone -reproduciendo las teleologías de los diversos discursos de modernización - epistemologías exógenas a los contextos latinoamericanos y establece narrativas que mantienen al subcontinente en un estatus periférico en la historia de la modernidad. Sin embargo, argumentos como éste ponen de relieve que la desconexión se puede entender también como producto del hecho de que los juicios sobre la historia global no siempre se han basado en los conceptos más acertados y adecuados dentro de la gama de interpretaciones que circulan alrededor de qué son y a qué aspiran los enfoques de este campo historiográfico. Aprensiones acerca de un eurocentrismo encubierto parecen infundadas, si el denominador común de las muchas propuestas sobre la naturaleza de la historia global se identifica con los dos objetivos fundamentales siguientes - para lo cual hay razones sólidas - : primero, la historia global se deja definir

${ }^{31}$ M. BRown, "The Global History of Latin America”. 
por el fin de superar perspectivas historiográficas "internalistas" que se limitan a enfocar estructuras y procesos dentro del marco de entidades territoriales dadas - del Estado nacional, en primer lugar - en el esfuerzo de explicar y comprender acontecimientos y desarrollos históricos; y, segundo, se caracteriza por la aspiración de descentrar perspectivas sobre un pasado que se ha analizado e interpretado por lo general alrededor de Occidente como el espacio histórico de referencia. Este concepto separa la historia global en particular de cualquier afán - característico de una cierta índole de la world history más antigua - por establecer en un alto nivel de abstracción teorías sobre macroprocesos a escala mundial. Ambos objetivos se distinguen también, por lo menos en una parte, de los textos sobre los global sixties, aunque esto no ha quedado ni explícito ni diferenciado. ${ }^{32}$

Comprender la historia global más bien como un enfoque historiográfico y no tanto como un objeto de estudio significa que los fenómenos históricos se estudian en sus contextos más amplios y en sus interrelaciones mediante grandes distancias geográficas y espacios culturales. La globalidad del fenómeno estudiado tiene el carácter de un objeto de investigación y no de un hecho histórico. La historia global - es importante subrayarlo - no es la historia de la globalización. La historia de la globalización forma parte de, pero no equivale a, la historia global. Esta última pierde demasiado potencial analítico si se limita al estudio de procesos globalizadores. Y a pesar del énfasis dado a la circulación de bienes, personas, ideas o conocimientos - a veces al grado de una verdadera fetichización de la movilidad-, la historia global no logra generar perspectivas y comprensiones fundamentalmente nuevas si su interés se reduce al estudio de flujos, redes e interacciones en las zonas de contacto

${ }^{32}$ Más explícito que otros fue ZoLov, "Introduction”, pp. 353-354; véase también Rutherford et al., "Introduction”; Christiansen y SCarlett, "Introduction". 
interculturales. ${ }^{33} \mathrm{Su}$ tarea es también dedicarse a los sectores menos entrelazados de las sociedades y a la pregunta de hasta dónde llegó la globalidad de los fenómenos examinados. Protagonistas del campo de la historia global han destacado reiteradamente que sus enfoques no aspiran a ser perspectivas totalizantes sobre el mundo - rasgo de una world history más antigua. Pero, a pesar de esto - o probablemente por esto-, los estudios que reclaman inscribirse en el campo de la historia global dicen en general poco acerca de lo global. Los trabajos que se sirven de la noción de los global sixties no son una excepción en este sentido. Mientras la mayoría de ellos se ha remitido a los sesenta globales como un marco de referencia sin examinar relaciones concretas $-\mathrm{y}$, por consiguiente, no comparte los enfoques de la historia global-, algunos estudios se han dedicado a la reconstrucción y al análisis de conexiones entre contextos más allá del espacio del Atlántico norte. Un ejemplo es West Germany and the Global Sixties de Timothy Scott Brown; otro, Refried Elvis de Eric Zolov. ${ }^{34}$ Brown sitúa su obra de 2013 explícitamente en el campo de los estudios de los sesenta globales. Zolov, cuyo libro se publicó en 1999, adoptará el concepto más adelante, pero con base en su interés en la historia del rock y de la contracultura en México. Sin embargo, ambos estudios - muy eruditos los dos - representan enfoques de historia transnacional, no de historia global.

Estudiar los global sixties requiere no sólo la reconstrucción del alcance geográfico de los fenómenos asociados con la década, sino también el análisis de lo que significaron en diferentes contextos alrededor del mundo. Esta tarea es más compleja que la investigación de "local appropriation[s] of global cultural products", como la conceptualizó Brown ${ }^{35}$ y como se encuentra

33 Para el concepto de las “zonas de contacto" véase PratT, Imperial Eyes.

${ }^{34}$ T. S. Brown, West Germany and the Global Sixties; Zolov, Refried Elvis.

35 T. S. Brown, West Germany and the Global Sixties, p. 7. 
también en Zolov. La idea de que los años sesenta veían el nacimiento de una cultura juvenil global, resultado de innovaciones tecnológicas que se manifestaron incluso en cambios en la movilidad y el uso de medios, está bien establecida. ${ }^{36} \mathrm{La}$ noción según la cual los procesos de globalización se realizan en forma de encuentros de lo "global" con lo "local", prevaleciente en general tanto en las ciencias sociales y culturales como en buena medida en los estudios de historia global, domina también los patrones interpretativos de la cultura juvenil global de los sesenta. Representaciones de la relación entre lo global y lo local en los global sixties como la siguiente, que se refiere al caso cubano, son frecuentes: "This version of the global youth culture experienced in Cuba in the field of popular culture was a 'Cubanized' version. [It] can, on continued reflection, be understood as a fascinating hybrid of the local and the global". ${ }^{37}$ Sin embargo, resulta difícil identificar elementos culturales, formas de protesta o agendas políticas a los cuales se pueda atribuir una existencia global en la cual circulaban alrededor del mundo para ser adaptados en lo sucesivo a las circunstancias particulares de diferentes contextos locales. Los elementos contraculturales siempre se manifestaban en contextos específicos: ser hippie se pensaba y se vivía en las circunstancias particulares de contextos locales, sea en San Francisco, L'viv, Johannesburgo o Huautla de Jiménez. ${ }^{38}$ Las formas de protesta no se imaginaban o se practicaban sino por actores concretos: el hecho de que la historia del movimiento estudiantil en México se cuenta en buena medida como una historia de violencia - de su escalación y de cómo abrió nuevos espacios políticos - se debe particularmente a la participación de pandillas, porros o jugadores de

\footnotetext{
${ }^{36}$ Por ejemplo, también en la historia (global) del corto siglo xx escrita por Hobsbawm, Age of Extremes, p. 33.

${ }^{37}$ Luke, "Listening to los Beatles", p. 289.

${ }^{38}$ Miles, Hippie; Risch, “Soviet 'Flower Children'”; LunN, “'Hippies, Radicals and the Sounds of Silence""; Estrada, Huautla en tiempo de hippies.
} 
futbol americano en el mismo. ${ }^{39} \mathrm{Y}$, por supuesto, las agendas políticas de los movimientos estudiantiles reflejaron en todo caso las condiciones específicas de las localidades en las cuales se habían producido: a pesar de las muchas condiciones compartidas en las sociedades de consumo, democracias representativas y la nueva izquierda, hasta los movimientos de protesta en países vecinos de Europa occidental, como Francia, la RFA y Suiza, mostraron - aparte de obvias similitudes - también diferencias significativas en sus orientaciones intelectuales que no sólo tenían que ver con sus distintas dinámicas, sino con desarrollos peculiares de las sociedades nacionales en la posgue$\mathrm{rra}^{40}$ Los elementos de la contracultura en Europa, las Américas, África y Asia estaban desde luego entrelazados. Las formas de protesta circulaban entre diferentes escenarios de expresiones de resistencia y oposición, y los movimientos estudiantiles se inspiraban mutuamente en sus rebeliones contra condiciones que en muchos aspectos compartían. ${ }^{41}$ Sin embargo, lo que se transfería dependía de actores concretos y era, en la mayoría de los casos, producto de contigencias. ${ }^{42}$

En lugar de buscar lo global en los conocimientos, ideas, normas o prácticas que circulaban, parece más adecuado pensarlo como la condición de las circulaciones. Lo global en la historia de los sesenta era sobre todo el espacio de comunicación, el marco de referencia para los actores locales. Desde muchos lugares del mundo los participantes en movimientos emancipatorios, en manifestaciones culturales de oposición y en la creación de ambientes alternativos a los sistemas de valores dominantes,

\footnotetext{
${ }^{39}$ Poo Hurtado, "Los protagonistas olvidados”; Rodríguez Kuri, “Los primeros días".

40 Véanse Gilcher-Holtey, "France”; Klimke, "West Germany”; Peter, "Switzerland".

${ }^{41}$ DeGroot, "The Culture of Protest".

${ }^{42}$ Esto lo subrayó también T. S. Brown, West Germany and the Global Sixties, p. 6.
} 
miraban hacia muchos otros lugares del mundo. En los global sixties existían conexiones entre diferentes espacios, pero no entre lo global y lo local. El sentido en el que estas relaciones lograron constituir fenómenos globales tiene que ser, como ya se dijo, objeto de estudios, incluso comparativos. Aunque algunos hechos y espacios pueden considerarse más importantes que otros: las historias de la nueva izquierda, de las drogas psicodélicas, del antiimperialismo y de la descolonización, de la música rock o folk, de la espiritualidad y la religión, de la Guerra Fría, del arte, de la moda o del turismo, todos mostraron topografías diferentes y estaban entrelazados de múltiples maneras. Como la historia del 68 no se deja contar alrededor del eje París-Berkeley, ${ }^{43}$ la historia de los global sixties tampoco puede organizarse de manera adecuada con base en la distinción entre centros y periferias. La importancia de lo que estaba sucediendo en el "tercer mundo", para muchos que en Europa y Estados Unidos aspiraron a trascendentales transformaciones sociales, políticas y culturales, se ha declarado una y otra vez una signatura de los sesenta. La Federación Socialista Alemana de Estudiantes (Sozialistischer Deutscher Studentenbund, SDS) - estructura cristalizadora del movimiento estudiantil en la RFA hasta 1968, probablemente la organización con el fundamento teórico más sólido entre los movimientos estudiantiles en Europa y uno de los principales representantes de la nueva izquierda - movilizó en 1967 y 1968 en primer lugar con el tema de la guerra en Vietnam, así como también entendió los movimientos de liberación en el "tercer mundo" como modelo para crear una conciencia revolucionaria; además, conceptualizó la aplicación de este modelo en términos de la teoría guevarista del foco. ${ }^{44}$ Michel Foucault subrayó la importancia de su experiencia en

${ }^{43}$ Alinder et al., "Introduction", p. 2.

${ }^{44}$ Klimke, The Other Alliance, pp. 40-74; Klimke, "West Germany", pp. 100-102. 
el levantamiento estudiantil en Túnez y no en el mayo francés para su comprensión del $68 .{ }^{45} \mathrm{Y}$, para dar un tercer ejemplo arbitrario entre muchos, fundadores del Black Panther Party, como Bobby Seale, Huey Newton o Eldridge Cleaver, se declararon influenciados de manera fundamental por la lectura del libro de Frantz Fanon Les damnés de la terre. ${ }^{46}$ Pero las cosas entre el "primer" y el "tercer mundo" - sin olvidar el "segundo" - ${ }^{47}$ eran aún más complejas. Jóvenes en los clubes de Bamako bailaban con la música de James Brown y Jimi Hendrix para expresar su inconformidad con la política cultural nacionalista de los líderes del movimiento indepentista de Mali. ${ }^{48}$ En La Habana, hubo jóvenes que participaron en la construcción de una nueva sociedad revolucionaria - esfuerzo fuertemente identificado con la juventud en el contexto cubano - escuchando al mismo tiempo a los Beatles, cuyas canciones se habían prohibido en la radio por un régimen que tenía por su parte un papel importante para las rebeliones juveniles alrededor del mundo y que estaba consciente de ello.49

A la luz de esta propuesta en torno a cómo pensar las relaciones entre lo global y lo local, hay sobre todo un argumento presentado en las publicaciones acerca de la globalidad de los sesenta que parece más sustancial que otros: la idea de que se pueden entender los sucesos y procesos asociados con los global sixties como causa y efecto de una conciencia global. Alrededor de esta propuesta se organizó incluso una de las más voluminosas e importantes antologías de textos sobre los sesenta globales: New World Coming: The Sixties and the Shaping of Global Consciousness. Los coordinadores del tomo partieron en su presentación de la sugerencia del economista, africanista

\footnotetext{
${ }^{45}$ Foucault, Remarks on Marx, pp. 131-146.

${ }^{46}$ Citados en Howe, Afrocentrism, p. 78.

${ }^{47}$ Véase Gorsuch y Koenker (coords.), The Socialist Sixties.

${ }^{48}$ SidibÉ, "Photo Essay".

${ }^{49}$ Luke, "Listening to los Beatles".
} 
y activista John S. Saul de delimitar los sesenta como "a crucial moment in the birth of a distinctive and novel kind of radical and global consciousness" ${ }^{50} \mathrm{Y}$ no han sido los únicos en hacer énfasis en este aspecto fundamental de los entrelazamientos entre las regiones del mundo. Arif Dirlik, por ejemplo, había propuesto ya, diez años antes, que "1968 [...] represented an unprecedented globalization of radical consciousness, which questioned national boundaries and the boundaries implied by the metaphor of three 'worlds' ". ${ }^{51}$ Un problema consistirá en determinar lo particular de esta conciencia, dado que también, antes de la segunda mitad del siglo xx, actores en busca de una transformación profunda de sus sociedades habían tenido algún conocimiento de las situaciones en países distantes y una idea de que éstas habían tenido que ver de alguna manera con los proyectos propios - aunque en aquellos tiempos esto se había denominado más bien "internacionalismo" o "cosmopolitanismo". ¿Era una diferencia cualitativa o se trató más bien de una diferencia en el grado del alcance? Pero aun con estas y otras preguntas abiertas, la evidencia de una conciencia de los actores que relacionaba los actos en que ellos estaban involucrados con lo que estaba sucediendo en otras partes del mundo ofrece un punto de partida en la historia para la reconstrucción y el análisis de lo global en los sesenta.

La cuestión de la conciencia está íntimamente ligada a dos aspectos cuya importancia suele subrayarse en la historiografía al abordar el tema de la globalidad de los años sesenta: los medios y los viajes. Particularmente los medios de comunicación siempre han estado en el centro de los esfuerzos por explicar la simultaneidad de hechos semejantes en la década. ${ }^{52}$ Noticias e

${ }^{50}$ SAUL, "Liberation Support and Anti-Apartheid Work", p. 127; RutherFORD et al., "Introduction", p. 3.

${ }^{51}$ Dirlik, "The Third World", p. 314.

52 Por ejemplo, Daniels, Year of the Heroic Guerrilla, p. 6; Fink, Gassert y JUNKER, "Introduction", pp. 9-13. 
imágenes circulaban alrededor del globo, transformando asuntos locales en informaciones y símbolos que causaban reacciones, se utilizaban y se resignificaban en contextos distantes. Un ejemplo notorio son las fotografías - como aquellas del jefe de la policía en Saigón ejecutando en plena calle con su pistola a un prisionero miembro del Vietcong, tomadas por Eddie Adams, o las de la masacre de My Lai, tomadas unas semanas después por Ronald L. Haeberle-, que contribuyeron de manera importante no sólo en Estados Unidos a los cambios en la opinión pública sobre la guerra en Vietnam. Era una amplia gama de medios por los cuales circulaban información, ideas, propaganda y obras culturales: periódicos, revistas, radio, televisión, carteles, películas, discos, libros. La contracultura, explicada de manera prominente como reacción a un sistema tecnocrático alienante, ${ }^{53}$ se difundía gracias a tecnologías modernas e incluso innovaciones tecnológicas. El consumo de la música - elemento central de lo que se ha denominado la revolución cultural de los sesenta $-{ }^{54}$ experimentó cambios drásticos con la expansión de la industria discográfica, la introducción de los transistores en la década anterior y también con la televisión: en la primera producción internacional de televisión vía satélite en vivo - titulada Our World - los Beatles interpretaron en junio de 1967 por primera vez All You Need Is Love ante la audiencia televisiva más grande en la historia hasta entonces, estimada en 400000000 de personas en 26 países alrededor del mundo. ${ }^{55} \mathrm{~L}$ representación de los fab four, con flores en el pelo, era también un mensaje en plena guerra de Vietnam. Pero los medios de comunicación no solamente servían como foro de protesta, sino que también se volvían un campo de batalla. Los conflictos entre los movimientos estudiantiles y la prensa en la RFA y en Italia son bien

${ }^{53}$ Roszak, The Making of a Counter Culture.

${ }^{54}$ T. S. Brown y Lison, "The Global Sixties in Sound and Vision", p. 5.

${ }^{55}$ Bennett, “Reapprising 'Counterculture’”, p. 3. 
conocidos. Y también en la ciudad de México, en agosto de 1968, estudiantes marcharon frente a las oficinas del diario Excelsior protestando contra la "prensa vendida". ${ }^{56}$ Aunque lo que se sabe de la política de información del Excelsior - y de otros medios de prensa- entre junio y agosto de 1968 no evidencia un amplio control del gobierno sobre lo que se escribía: ${ }^{57}$ los debates y conflictos ponen de relieve la necesidad de analizar de manera diferenciada una historia compleja. El desempeño de los medios en los procesos políticos y culturales de los años sesenta era heterogéneo y la circulación de información, en efecto, también se veía expuesta a una serie de limitaciones tanto políticas como técnicas y sociales. No todo era flujo e interconexión. El control del Estado sobre los medios de comunicación podía restringir el acceso a noticias y productos culturales tanto como la falta de disponibilidad de aparatos o infraestructuras podía hacerlo. Los dos factores también podían combinarse como, por ejemplo, en el caso de Sudáfrica, donde el gobierno del Partido Nacional, temiendo el potencial de esta tecnología para socavar su poder, impidió la introducción de la televisión.

En Sudáfrica en los años sesenta la circulación de las nuevas ideas encontró otros caminos - y se basó en otros medios como, por ejemplo, revistas, libros o discos. Lo que resultó más dificil de controlar para el régimen del apartheid fue la movilidad individual - sobre todo en el caso de los jóvenes blancos de clase media que frecuentaban las universidades del país. ${ }^{58}$ No sólo en Europa y Estados Unidos los viajes de jóvenes de clase media a otros países se volvieron en los sesenta un fenómeno de masas. Surgió una cultura del viaje en la cual se superponían motivos

\footnotetext{
${ }^{56}$ Brewster, “The Student Movement of 1968 and the Mexican Press”, p. 173.

57 Brewster, "The Student Movement of 1968 and the Mexican Press". Para una extensa bibliografía de las publicaciones en la prensa sobre el movimiento estudiantil en México, véase Ocampo (comp.), México, conflicto estudiantil. ${ }^{58}$ Lunn, “'Hippies, Radicals and the Sounds of Silence”", pp. 3, 7, 50, 84, 106-107, 125-130.
} 
políticos de la movilidad con anhelos de una liberación personal, o de una aventura con la búsqueda de nuevas experiencias espirituales o de drogas. La nueva cultura contribuía a una intensificación de intercambios por medio de espacios culturales hasta forjar nuevas identidades que trascendían fronteras nacionales. Las movilizaciones políticas de los sesenta no sólo dieron lugar a un internacionalismo renovado sino también a actitudes de rebelión que negaron la importancia de las nacionalidades. Lo ilustraron de forma prominente los líderes de los movimientos estudiantiles en Europa: Daniel Cohn-Bendit, protagonista de la movilización de los estudiantes en el mayo francés, era - precisamente-alemán; Rudi Dutschke, primer activista del sDs en la RFA, provenía de la República Democrática Alemana (se había casado con una estadounidense y bautizó a uno de sus hijos Che); Tariq Ali, figura destacada de la nueva izquierda en Gran Bretaña, había nacido en Lahore. La prueba más ilustre de que la movilidad de jóvenes politizados de clase media no se limitaba a contextos europeos - junto con sus actuales o antiguos territorios coloniales - y a Estados Unidos la dio probablemente el Che Guevara. Habían sido los beatniks quienes ya en los años cincuenta habían introducido los viajes como elemento básico de una (contra)cultura juvenil o hasta una forma de vida alternativa. La obra clave de la beat generation, de Jack Kerouac, On the Road (1957), celebró una nueva manera de viajar. Y mientras que sus dos protagonistas, Sal Paradise y Dean Moriarty, también pusieron a México en el mapa de los hipsters, el libro The Psychedelic Experience, de Timothy Leary (1964) - que asimismo tenía importantes raíces mexicanas-, relacionaba el uso de LSD con el budismo tibetano. ${ }^{59}$ Cientos de miles, probablemente millones de europeos, estadounidenses $\mathrm{y}$ australianos viajaron en los años sesenta y comienzos de los

59 Véanse Kerouac, On the Road; Leary, Metzner y Alpert, The Psychedelic Experience. 
setenta en el hippie trail hacia Asia y África del Norte inspirados en la idea de dejar atrás el materialismo de la sociedad de consumo occidental y abrir su mente a la espiritualidad de un Oriente místico, también con la ayuda de "afgano negro", "marocano morado" o psicodélicos por lo menos asociados con el este. ${ }^{60}$ Junto con los motivos del viaje también había una gran variedad de destinaciones. Y al igual, las opciones respecto a los medios de transporte se ampliaron: a pesar de la popularidad del autostop o de viajes en autobús, el hecho de que los viajes aéreos se volvieron más asequibles era de una relevancia particular en cuanto a fenómenos de entrelazamientos a grandes distancias geográficas. Pero, aunque los jóvenes viajaban alrededor del mundo, las destinaciones eran en muchos casos muy específicas: como la noción del trail insinuaba, los viajeros contraculturales a Asia se movían a lo largo de un itinerario bastante definido de Estambul a Teherán, Kabul, Lahore y Nueva Delhi, y de ahí a Katmandú, Dhaka, Sri Lanka o Goa. Dentro de Europa los activistas hicieron su recorrido a lo largo de los supuestos centros de las movilizaciones políticas: Amsterdam (en donde en 1966 hasta la agencia municipal de turismo invitó a extranjeros a excursiones exclusivas para "Meet the Provos!"), ${ }^{61}$ París (en donde los turistas comunes se ausentaron en la primavera y el verano de 1968 mientras que las visitas de jóvenes viajeros, atraídos por la efervescencia política, alcanzaron cifras récord), ${ }^{62}$ Berlín, Praga ${ }^{63}$ Y también en México existían puntos fijos del peregrinaje hippie: entre ellos la capital de la República, Acapulco, Huautla de Jiménez, Zipolite y Palenque. ${ }^{64}$ En comparación,

\footnotetext{
60 Gemie e Ireland, “The Hippie Trail”.

${ }^{61}$ PAs, “Images d'une révolte ludique”, p. 368.

${ }^{62}$ Jean Ginier, Les touristes étrangers en France pendant l'été, París, 1969, p. 297, citado en Jobs, “Youth Movements”, p. 378.

63 Jobs, "Youth Movements".

${ }^{64}$ Marroquín, La contracultura como protesta, pp. 35-37; José Agustín, La contracultura en México, pp. 73-76; Estrada, Huautla en tiempo de hippies;
} 
pocos jóvenes de América Latina, Asia y África viajaban a otros continentes; la mayoría de ellos se movían en sus países - el caso de los hippies mexicanos es ilustrativo- o en una región más grande. Un grupo situado entre los viajeros y los migrantes, pero de relevancia para la transferencia de información e ideas, eran los jóvenes que cursaron sus estudios en universidades europeas o estadounidenses. Pero también ellos confirman la imagen de entrelazamientos más bien parciales que resultaron de la nueva cultura de viajes en los sesenta.

Si los medios y los viajes pueden considerarse condiciones básicas de lo que se ha designado como la conciencia global de los sesenta, los dos aspectos ponen de relieve al mismo tiempo la necesidad de preguntar por las interrelaciones concretas y sus límites. Aunque la idea de actuar en un contexto global de rebeliones contra autoridades establecidas y valores dominantes era sin duda algo presente entre muchos de los que participaron en las movilizaciones políticas y las manifestaciones contraculturales, la noción de la conciencia global tiene que examinarse para evitar conclusiones erróneas. Antes de poder dedicarse a analizar su papel en los procesos de desafío y transformación, hay que emprender el estudio de lo que esta conciencia incluía: ¿cuáles eran los acontecimientos y fenómenos alrededor del mundo que se tomaron en cuenta? Además, por supuesto, hay que preguntar hasta dónde llegó la conciencia: ¿quiénes sabían qué de las situaciones en qué otras partes del mundo? Y, finalmente, el diagnóstico del alcance de una conciencia de cambio radical está relacionado de forma indisoluble con la cuestión de cómo se tomó en cuenta lo que sucedía en otros lugares del mundo, con la cuestión del significado local de los conocimientos que circulaban a grandes distancias. Obviamente, estos análisis no tienen que cubrir la totalidad del planeta para poder llegar a una conclusión acerca de la globalidad del fenómeno

Zolov, Refried Elvis, pp. 107-110. 
estudiado. No es necesario comprobar interrelaciones hasta todos los lugares de este mundo para poder calificar legítimamente el fenómeno como global. Pero una cierta extensión de la base empírica es imprescindible para poder hacer plausible el argumento de la globalidad de, por ejemplo, una conciencia compartida en la búsqueda de nuevas formas de organización social y política.

Estudiar la globalidad de los sesenta con base en un concepto que entiende lo global en primer lugar como un marco de comunicación dentro del cual desde muchos lugares del mundo se tomó en consideración lo que sucedía en muchos otros lugares del mundo es útil en particular también para examinar los diferentes alcances de las interacciones transfronterizas. No todo lo que no cabe dentro del container nacional del análisis histórico y que estaba relacionado con procesos que tenían lugar en espacios distantes, o que formaba parte de estructuras de grandes alcances geográficos, se deja calificar como fenómeno global. ${ }^{65}$ Es importante no confundir lo transnacional con lo global. Y estudiar los significados específicos de los entrelazamientos transnacionales o globales implica asimismo tomar en cuenta los efectos divisorios de los mismos. Frente a las manifestaciones contraculturales en México en los años sesenta y a inicios de los setenta no sólo el gobierno alegó intereses de la nación contra lo que denunció como una conspiración extranjera y valores antimexicanos. También la izquierda - no sólo la doctrinaria - mostró reacciones nacionalistas contra fenómenos antiautoritarios que consideraba nocivos para el proyecto de la transformación del sistema político y social. Es conocida la carta de Carlos Monsiváis enviada (desde Inglaterra) a Abel Quezada con motivo del festival de Avándaro - el "Woodstock mexicano" - ${ }^{66} \mathrm{y}$ publicada (sin haber avisado al autor) en

${ }^{65}$ Cooper, "What Is the Concept of Globalization Good for?".

${ }^{66}$ José Agustín, La contracultura en México, p. 85. 
septiembre de 1971 en Excelsior, en la cual polemiza: “¿Qué es la Nación de Avándaro? Grupos que cantan, en un idioma que no es el suyo, canciones inocuas [...] Pelo largo y astrología, pero no lecturas y confrontación crítica [...] Es uno de los grandes momentos del colonialismo mental en el Tercer Mundo". ${ }^{67}$

\section{PERSPECTIVAS}

Poco después, un Monsiváis apenado declaró en una carta, esta vez publicada por Siempre!, su "bochorno [...] por haber caído, siquiera un rato, en el bajo clima de moralismo" y por haberse adherido "a la órbita de moralina de los defensores típicos de la pureza”. ${ }^{68}$ A pesar de esta relativización, la posición de Monsiváis se inscribió en una tradición de crítica que se centraba en una supuesta actitud apolítica de los hippies, como lo confirmó más adelante su ensayo sobre "La naturaleza de la onda", publicado en el libro Amor perdido (1977) - un texto introducido también con el famoso eslogan de Leary "Drop out, Tune in, Turn on" ${ }^{69}$ Ideas preconcebidas, por no decir prejuicios, como éstas, dominaron durante décadas las perspectivas sobre la relación de la contracultura y las movilizaciones políticas de los años sesenta y setenta en México. Antes, como después de Tlatelolco, los hippies fueron sospechosos para la izquierda mexicana. Y los miembros de la misma tuvieron por muchos años más una influencia decisiva en los debates sobre el 68, también en el marco académico. Estos puntos de vista, que se pueden calificar como ideologizados, han comenzado a perder peso en los últimos años. Una nueva generación de historiadores ha empezado a ocuparse de los sesenta, no sólo en el caso mexicano.

${ }^{67}$ Citado en José Agustín, La contracultura en México, p. 88.

${ }^{68}$ Citado en Fernando Figueroa, “Avándaro según tres Monsiváis”, en El Universal (11 sep. 2011) http://archivo.eluniversal.com.mx/cultura/66353. html; Consultado el 5 de febrero de 2017.

69 Monsiváis, Amor perdido, p. 228. 
Pero también entre los representantes de esta generación, y que forman parte del campo de investigación de los global sixties, ha sobrevivido la idea de que una cultura hippie individualista, apolítica - o antipolítica-, dedicada al dropping out y al retiro de la sociedad, no tenía mucho que ver con los movimientos de protesta en los países del tercer mundo que precisamente lucharon por la participación, la representación y la inclusión. Hasta se ha identificado la ausencia de una relevancia política en la contracultura como una de las importantes diferencias entre el tercer mundo y Occidente en los sesenta globales: "the Third World lacked any significant or united countercultural movement. The counterculture was an important if not central characteristic of the Western student movement”. Ha sido precisamente en la introducción de The Third World in the Global 1960s donde se ha argumentado de esta manera. ${ }^{70}$ Tratando de esbozar una integración de la historia de los sesenta en México con las perspectivas de la historia global, las observaciones concluyentes de esta contribución se concentrarán en dos aspectos - retomando el comentario a la afirmación del empleado de Correos Leopoldo García Trejos citada al principio-: el análisis de la relación entre activismo político y contracultura, y el estudio de los procesos que tuvieron lugar en México como parte de una historia más amplia.

No parece posible llegar a una visión adecuada de la globalidad de los sesenta como década de protesta - mucho menos de 1968 como año de revolución - ${ }^{71}$ sin considerar las interdependencias entre lo político y lo contracultural. A la luz de la

\footnotetext{
70 Christiansen y Scarlett, "Introduction" al volumen en el cual los coordinadores dejaron también constancia de que "[t]his volume is noticeably devoid of any equivalent countercultural movement that resembles the Western experience”, pp. 8-9. Esto incluyó un artículo sobre México dedicado al movimiento estudiantil de 1968: SLOAN, "Revolution on the National Stage". ${ }^{71}$ Daniels, Year of the Heroic Guerrilla, pp. 3-15; Suri, The Global Revolutions of 1968.
} 
centralidad del tema, hasta ahora ha habido relativamente pocos esfuerzos de análisis sistemático y diferenciado de estas relaciones desde una perspectiva internacional o transnacional más amplia. Pero no sólo queda mucho por entender sobre las interdependencias entre movilizaciones políticas y manifestaciones contraculturales más allá de los diferentes contextos nacionales, sino también por precisar respecto a la conceptualización del estudio de este objeto. A primera vista parece contundente el argumento de Jeremi Suri de que la contracultura de los sesenta - la cual situó de manera prominente en el contexto político de la Guerra Fría - era más explícitamente politizada que sus antecesoras en la posguerra. ${ }^{72}$ Pero probablemente sería más adecuado hablar de una transformación de las relaciones entre política y contracultura - lo que implicaría diferenciar las esferas y estudiar interacciones-, dada la fundamental tensión que se ha reconocido entre las dos no sólo en esta década. En los años noventa, el mismo Leary generalizó, en una breve introducción a un tomo que se dedicó precisamente a la longue durée de fenómenos contraculturales:

Counterculture may be found in (sometimes) uneasy alliances with radical, even revolutionary political groups and insurrectionary forces, and the memberships of countercultures and such groups often overlap. But the focus of counterculture is the power of ideas, images, and artistic expression, not the acquisition of personal and political power. $^{73}$

Una tercera opción podría ser el argumento de que la contracultura, particularmente en los sesenta, representaba en su postura anti-establishment - no sólo, pero también - esfuerzos por

${ }_{72}$ SURI, "The Rise and Fall of an International Counterculture", p. 95.

73 Timothy Leary, "Foreword", en Goffman y Joy, Counterculture through the Ages, p. x. 
someter a prueba lo que se consideraba como político. En este sentido, se puede identificar una dimensión política, por ejemplo, también en la idea de Leary de haber encontrado en la psilocibina y el LSD no sólo sustancias de terapia individual sino la solución a los males de la sociedad - reproducida en México por aquellos hippies que pensaron lograr la transformación social mediante la diseminación masiva de LSD en los sistemas de abastecimiento público de agua potable. ${ }^{74}$

En términos generales, se ha señalado lo que unía el activismo político y la contracultura en los sesenta - los overlaps de los cuales Leary habló - : la búsqueda de una existencia considerada como más auténtica contra la percibida alienación en sociedades que ofrecían para los sectores más grandes de ellas cierto bienestar material pero al mismo tiempo presentaban una discrepancia sensible entre las promesas de libertad - y de democracia - y la realidad de los sistemas políticos y la straight society, la sociedad respetable, cuyos valores reproducían los conflictos de la Guerra Fría. La circunstancia de que la percepción de injusticia, que representa una base primordial para la mayoría de los movimientos de protesta, estaba íntimamente relacionada con las experiencias de la vida cotidiana, ${ }^{75}$ era responsable del hecho de que lo político y lo contracultural se podían mezclar casi hasta ser indistinguible su oposición a las instituciones que representaban el orden dominante: desde el gobierno hasta la escuela y la universidad, desde los medios de comunicación hasta la familia. Aquí se unieron la lucha antiimperialista con el combate contra estructuras autoritarias y represoras dentro de la propia sociedad nacional. De la teorización de estos vínculos se encargó la nueva izquierda, que se distinguía de la izquierda tradicional incluso por pensar la emancipación en un sentido más amplio, trascendiendo el campo de las relaciones económicas hacia las

74 José Agustín, La contracultura en México, p. 79.

75 Crossley, "Protest and Lifestyle", pp. 69-70. 
relaciones interpersonales, atacando jerarquías y dominación en todos los aspectos de la vida social. A pesar de las tensiones entre la nueva izquierda y los hippies, los últimos pueden concebirse de alguna manera - como ya lo hizo Theodore Roszak en su obra fundamental sobre la contracultura - como pioneros utópicos que aspiraban a la realización de un estilo de vida que se proyectaba desde la crítica social de la nueva izquierda. Las nuevas formas de convivencia que buscaron los hippies representaron en cierto modo una base cultural para la política de la nueva izquierda. ${ }^{76}$

Tales análisis se han concentrado hasta ahora sobre todo en Europa y Estados Unidos. Sin embargo, especialistas en la historia de la contracultura han puesto énfasis en el carácter global de la cultura hippie de los años sesenta y setenta, contrastándola con las contraculturas de la década anterior, en la cual, por ejemplo, los teddy boys habían representado fenómenos mucho más limitados. ${ }^{77}$ Para el contexto mexicano, José Agustín dejó claro que se habían dado pocos beatniks en México - a pesar de las estancias de William Burroughs y Kerouac en el país. ${ }^{78} \mathrm{Y}$ Zolov no trató a los rocanroleros de los años cincuenta en el país como representantes de una contracultura. ${ }^{79}$ Pero ambos, como también Enrique Marroquín, coincidieron en considerar a los bippies, y sobre todo a la Onda, como un fenómeno de masas: ${ }^{80}$ en el festival de Avándaro, uno de los pocos acontecimientos que permitieron una estimación cuantitativa, se reunieron más de 200000 jóvenes. En particular en el caso de la Onda - descrita

\footnotetext{
${ }^{76}$ Roszak, The Making of a Counter Culture, p. 66.

77 Bennett, "Reapprising 'Counterculture", p. 3; Jefferson, "Cultural Responses of the Teds".

78 José Agustín, La contracultura en México, pp. 28. Para Kerouac en México véase García-Robles, El disfraz de la inocencia.

79 Zolov, Refried Elvis, pp. 17-92.

${ }^{80}$ Marroquín, La contracultura como protesta; José Agustín, La contracultura en México, pp. 59-98; Zolov, Refried Elvis, pp. 93-233; Zolov, "Mexico's Rock Counterculture".
} 
por José Agustín como "las manifestaciones culturales de numerosos jóvenes mexicanos que habían filtrado los planteamientos jipis a través de la durísima realidad del movimiento estudiantil" -, la estrecha interrelación de los procesos contraculturales y políticos ha empezado a reconocerse por lo menos desde el 20 aniversario del 68 de manera creciente. ${ }^{81}$

La contribución probablemente más importante en los últimos 20 años a la exploración del tema de la contracultura en México en los años sesenta la han representado los trabajos de Eric Zolov. Enfocándose sobre todo en la música rock, que utilizó en su monografía Refried Elvis "as a keyhole into modern Mexican society, allowing us to view and discuss the crisis of revolutionary nationalism", ${ }^{82}$ Zolov ha proporcionado amplios conocimientos sobre la aparición y el desarrollo del elemento central de la contracultura en México; ha puesto de relieve las contradicciones, tensiones y ambigüedades de una contracultura que se puede interpretar como un fenómeno de la "modernidad reflexiva"; ${ }^{83}$ ha expuesto de manera clara la dimensión política de una contracultura que desafiaba paternalismos en una sociedad gobernada por un régimen que se designaba a sí mismo "familia revolucionaria" - y un presidente que se entendía como padre de la nación -, legitimando su poder tradicionalmente en buena medida en las narraciones de un nacionalismo cultural; también ha hecho comprensible la contracultura en México en sus conexiones transnacionales, en particular con Estados Unidos. Zolov ha establecido así una base sólida para la integración de la historia mexicana de protesta en los sesenta al campo de investigación de los global sixties, una integración que él mismo protagoniza. ${ }^{84}$

${ }^{81}$ José Agustín, La contracultura en México, p. 83. Para una publicación de 1988 véase, por ejemplo, la entrevista con Javier Molina en Bellinghausen (coord.), Pensar el 68, pp. 227-232.

${ }^{82}$ Zolov, Refried Elvis, p. 2.

${ }_{83}$ Véase, por ejemplo, BEcK et al., Reflexive Modernization.

${ }^{84}$ Véase Zolov, "Introduction" y el anuncio de un nuevo libro. 
A pesar de todo el trabajo que ya se ha realizado en este terreno - no sólo por Zolov sino también por otros autores-, mucho acerca de la relación entre política y contracultura en México en los años sesenta en general, y en el movimiento estudiantil de 1968 en particular, ha permanecido en el nivel de explicaciones más bien generalizantes y de deducciones analógicas. Esto tiene que ver también con la naturaleza de la categoría de la contracultura, que es, según Barry Miles, un loose label - como también aquella de los hippies. ${ }^{85}$ A pesar de la crítica que se le ha hecho como categoría analítica - y que comparte con la "subcultura",$-{ }^{86}$ es un término que se sigue utilizando con ciertos beneficios, especialmente en el estudio de fenómenos de los años sesenta, también porque representa una expresión de la época. Como tal, y en contraste con la "subcultura", le es inherente la idea de una transnacionalidad. Las contraculturas han reorganizado identidades, particularmente trascendiendo comunidades nacionales. La historia global puede ofrecer, por ende, enfoques adecuados para la reconstrucción y el análisis de fenómenos contraculturales. En esto, puede servirse de un concepto renovado que, en una posible formulación, entiende por contraculturas "fluid and mutable expressions of sociality that manifest themselves as individuals temporarily bond to express their support of and/or participation in a common cause, but whose everyday lives are in fact simultaneously played out across a range of other cultural terrains" ${ }^{87}$

Esta manera de comprender el término no sólo supera la dicotomía entre dominación y oposición, sino también su función de categorizar diferentes grupos sociales. Es un concepto apropiado para el análisis de una situación histórica muy compleja,

${ }^{85}$ Miles, Hippies, p. 9.

${ }^{86}$ HuQ, "Protest in the Research on Sub- and Countercultures"; Chaney, "Fragmented Culture and Subcultures". Fundamental para la categoría de la "subcultura": Hall y JefFerson, Resistance through Rituals.

${ }^{87}$ BennetT, "Reapprising 'Counterculture”, p. 10. 
en la cual no sólo los contornos de la contracultura no eran casi discernibles, sino también el movimiento estudiantil se presentaba sumamente heterogéneo: jóvenes que adoptaron algunos elementos de la contracultura y otros que no lo hicieron; que se identificaron como hippies y participaron al mismo tiempo en el movimiento estudiantil; que se retiraron incluso después de la masacre de Tlatelolco de compromisos de activismo político y se volvieron chavos de la Onda, o dejaron atrás su identidad contracultural y se radicalizaron; que pertenecían a la clase alta, y así de alguna manera al establishment, y a la vez fueron hippies o formaron parte del movimiento estudiantil; que eran estudiantes de izquierda y escucharon a Cream o a Eric Burdon and the Animals en lugar de corridos de la revolución mexicana o la nueva trova, fumaron marihuana o experimentaron con sustancias psicodélicas. No es de ninguna manera paradójico que la historia global ofrezca nuevos impulsos para análisis de este tipo a nivel micro. Aunque muchos historiadores en la actual coyuntura de la historia global se concentran en -o se limitan a- observar flows y reconstruir relaciones transfronterizas, el verdadero potencial de la historia global se puede desarrollar solamente con base en su capacidad de llegar a comprender el significado que tenían los entrelazamientos reconstruidos para los desarrollos locales. Y esto requiere estudios diferenciados de actores y situaciones históricas específicas.

En los últimos años, toda una serie de monografías no sólo ha puesto en evidencia la existencia de una contracultura relevante en diferentes países de América Latina en "los largos años sesenta”. También se ha dedicado de manera prominente al estudio de la misma en sus interrelaciones con los procesos políticos de la época. Tanto la obra de Christopher Dunn sobre el movimiento artístico Tropicália en Brasil, como las publicaciones de Vania Markarian sobre el movimiento estudiantil entre izquierda y contracultura en Uruguay, de Valeria Manzano sobre la "era de la juventud” en Argentina y de Patrick Barr-Melej sobre el 
bippieismo en Chile, han dejado en claro la particularidad de los desarrollos respectivos en cada contexto nacional. ${ }^{88}$ No sólo el régimen posrevolucionario priista en México representó un caso especial entre las constelaciones políticas en las cuales se dieron los movimientos contraculturales en América Latina de los años sesenta y principios de los setenta: la dictadura militar que se instaló en Brasil a mediados de los años sesenta - mientras los golpes de las fuerzas armadas en Chile y Argentina pusieron definitivamente fin a los "largos años sesenta" en América del Sur en 1973 y 1976, respectivamente-, la creciente crisis del tradicional sistema político bipartidista bajo las condiciones de deterioro de la economía y de la polarización social en Uruguay -imaginado por sus ciudadanos como "Suiza de América"-, el peronismo en Argentina y el gobierno de la Unidad Popular, que prometía un camino democrático al socialismo en Chile, todos crearon condiciones políticas sumamente específicas para las movilizaciones emancipadoras que buscaron una liberación de convenciones sociales y culturales de la posguerra percibidas como opresivas e injustas. Al mismo tiempo, los autores, sobre todo los de las obras más recientes, han situado su trabajo en el contexto de la coyuntura internacional de los estudios sobre juventud, movimientos estudiantiles, contracultura y transformaciones políticas en los long sixties, uno de ellos hasta explícitamente dentro de los estudios sobre los global sixties. ${ }^{89}$ Sin puntualizar aquí los respectivos méritos considerables de los trabajos en enriquecer la comprensión de las transformaciones culturales y políticas que se dieron en la época en los distintos contextos nacionales; hay que constatar que su producción de nuevos conocimientos se dio más que nada dentro de los marcos epistemológicos de las historias nacionales. Dada la

${ }^{88}$ Dunn, Brutality Garden; Markarian, El 68 uruguayo; Manzano, The Age of Youth in Argentina; Barr-Melej, Psychedelic Chile.

${ }^{89}$ Barr-Melej, Psychedelic Chile, p. 12. 
especificidad histórica de cada caso nacional, los estudios no sólo se han enfocado últimamente en diferentes aspectos de la temática de la contracultura y la política. A pesar de que todas las publicaciones han realzado el carácter transnacional de la contracultura, han carecido casi por completo tanto de perspectivas comparativas - aunque, desde luego, han tomado en cuenta las investigaciones realizadas sobre otros países latinoamericanos - como de esfuerzos por reconstruir de manera pormenorizada transferencias e interacciones entre movimientos contraculturales en diferentes sociedades nacionales - dentro de América Latina y más allá de ella - y analizarlas en sus significados para desarrollos locales. Por ende, continuamos sin saber mucho sobre las comunidades entre los diferentes movimientos contraculturales en América Latina en los años sesenta, por ejemplo, respecto a sus informaciones sobre percepciones de y posturas hacia constelaciones y desarrollos internacionales y transnacionales. Y lo mismo en relación con los entrelazamientos entre ellos: por ejemplo, respecto a contactos personales - por medio de viajes o de otra manera-, al consumo de productos culturales como música o literatura (dado el idioma compartido), o la circulación de narraciones, imágenes y estilos de vida. En general, la mayoría de los estudios mencionados ha tratado la contracultura como un producto genuinamente estadounidense y europea cuyos elementos fueron adoptados luego en espacios latinoamericanos considerados por los autores explícitamente como periféricos.

La integración de la historia mexicana - como de la brasileña, la uruguaya, la argentina o la chilena - de los años sesenta en las perspectivas de la historia global tiene que ir más allá del estudio de la historia nacional en sus contextos globales. El propósito debe ser más bien hacer de las historias nacionales parte de una historia multicéntrica en la cual - mediante la combinación de estudios de transferencias y de una comparación sistemática- se aspire a una todavía mejor comprensión de desarrollos 
locales, de los entrelazamientos entre éstos a nivel mundial y de procesos más generales. En el caso del 68 se podría llegar a una mejor comprensión de lo que hasta ahora no se ha entendido muy bien: la notable simultaneidad de hechos. En el caso de los global sixties, uno de los objetivos primordiales de una historia multicéntrica global tiene que consistir en llegar a conclusiones acerca de su globalidad y del significado de la misma.

Integrar a México en una historia multicéntrica no significa que el país tenga que ser descubierto como escenario de los sesenta globales. Esto ya no es necesario de ninguna manera. Por lo menos el movimiento estudiantil y su destino han sido tomados en cuenta en la bibliografía sobre 1968 una y otra vez. Pero significa, entre otras cosas, romper con las premisas difusionistas establecidas en la manera de analizar y comprender las relaciones entre diferentes regiones del mundo. En el caso de la contracultura, Zolov expressis verbis contó una historia de la "mexicanización” de la cultura hippie..$^{90}$ Con esto, describió un proceso unilateral. Sin embargo, la contracultura hippie era un fenómeno sumamente transnacional en el sentido de que se desarrolló desde el comienzo, a mediados de los sesenta, en interacciones transfronterizas - y por ende, una expresión como “jipitecas”, introducida por Marroquín para señalar la identificación de los bippies mexicanos con elementos de las culturas indígenas de su país, parece redundante. ${ }^{91}$ La cultura de los hippies no creció primero en un lugar - Estados Unidos - para ser transferido después a otros, entre ellos México. Una historia multicéntrica de los hippies no sólo prestaría más atención a las predisposiciones culturales endógenas de, por ejemplo, la reapropiación de la cultura indígena por los jóvenes mexicanos, dada la centralidad de lo indígena en las construcciones de la identidad nacional en el México posrevolucionario. Sobre todo, preguntaría también

90 Zolov, Refried Elvis.

91 Marroquín, La contracultura como protesta. 
por el significado de México en la historia transnacional de la cultura hippie. Gracias incluso a Robert Gordon Wasson, los beatniks, y más adelante a Leary, México era un escenario de esta cultura desde los comienzos. Lo que José Agustín describió como la invasión silenciosa de Huautla de Jiménez empezó tan temprano como 1962. ${ }^{92}$ En los años siguientes, Bob Dylan, John Lennon y Mick Jagger eran solamente los visitantes más prominentes de María Sabina en la Sierra Mazateca. Pero, además de las drogas, México hizo contribuciones importantes a la cultura hippie. Después del concierto de Carlos Santana en el festival de Woodstock, por ejemplo, la fusión del rock con la música latina se había establecido definitivamente en el repertorio musical del hippieismo. La multidireccionalidad de las transferencias, tanto en el ámbito cultural como en el político, no es, por supuesto, una nueva premisa, sino objeto de estudio en la historia global. Así, respecto al activismo político se puede constatar algo muy parecido al diagnóstico respecto a los movimientos contraculturales: son más que nada indicios los que hay de una conciencia entre los actores de lo que estaba sucediendo en otros países. Sobre transferencias, intercambios o cooperaciones concretas, se continúa sin saber mucho. ${ }^{93} \mathrm{El}$ estudio concreto de entrelazamientos desde una perspectiva multicéntrica, que incluye la reconstrucción de alcances y el análisis de significados, está dirigido a la generación de comprensiones diferenciadas respecto a espacios, tiempos y fenómenos. México y, por ejemplo, Chile no tenían la misma importancia para la cultura hippie transnacional; representaban experiencias políticas sumamente diferentes en los imaginarios de la “nueva izquierda” en América Latina, Estados Unidos y Europa, y todos los significados fueron sujetos a cambios a lo largo de la década.

\footnotetext{
92 José Agustín, La contracultura en México, pp. 73-74.

93 Este aspecto de la historia de los sesenta se ha estudiado de forma detallada en el caso de Estados Unidos y Alemania. Klimke, The Other Alliance.
} 
Sin embargo, los enfoques de la historia global no sólo se basan en el estudio de transferencias e interacciones. En el campo de investigación de los global sixties tampoco se han realizado hasta ahora comparaciones sistemáticas. En el caso mexicano éstas podrían producir nuevos conocimientos, por ejemplo, respecto a la cuestión de las transformaciones que resultaron de los sucesos de la década - una cuestión que se ha discutido sobre todo concentrándose en las especificidades del régimen posrevolucionario. Pero el fin de adoptar las perspectivas de la historia global no sólo consiste en llegar a una mejor comprensión de la historia nacional mexicana. También se trata de entender mejor lo que sucedió en diferentes partes del mundo y de poder analizar procesos más allá de los marcos nacionales de la historia -lo que pone de relieve una vez más que el enfoque global de la agenda de investigación sobre los global sixties no puede limitarse a la agregación de estudios sobre contextos nacionales alrededor del mundo. En el listado de los periodos clave a los cuales los historiadores deberían dedicar sus estudios para integrar la historia de América Latina en la historia global, presentado por Matthew Brown, la historia contemporánea está extrañamente ausente. ${ }^{94}$ Los años sesenta definitivamente se prestan para dar uno de los primeros pasos en la dirección hacia una mayor integración.

\section{REFERENCIAS}

Abdulhadi, Rabab Ibrahim, "Whose 1960s? Gender, Resistance, and Liberation in Palestine”, en Dubinsky et al. (coords.), 2009, pp. 13-23.

Alinder, Jasmine et al., “Introduction”, en SHERman et al. (coords.), 2013, pp. 1-17.

Anderson, Benedict, Imagined Communities. Reflections on the Origin and Spread of Nationalism, Londres, Verso, 1983.

${ }_{94}$ M. Brown, “The Global History of Latin America”, pp. 376-382. 
Aréchiga Robles, Rubén et al., Asalto al cielo. Lo que no se ha dicho del 68, México, Oceano, 1998.

Barr-Melej, Patrick, Psychedelic Chile: Youth, Counterculture, and Politics on the Road to Socialism and Dictatorship, Chapel Hill, University of North Carolina Press, 2017.

Beck, Ulrich et al., Reflexive Modernization. Politics, Tradition and Aesthetics in the Modern Social Order, Stanford, Stanford University Press, 1994.

Bellinghausen, Hermann (coord.), Pensar el 68, México, Cal y Arena, 1988.

Bennett, Andy, "Reapprising 'Counterculture”, en Volume!, 9: 1 (2012) http://volume.revues.org/3499. Consulta, 5 de febrero de 2017.

Bennett, Andy y Keith KaHn-Harris (coords.), After Subculture: Critical Studies in Contemporary Youth Culture, Basingstoke, Palgrave, 2004.

Brewster, Claire, "The Student Movement of 1968 and the Mexican Press: The Cases of Excélsior and Siempre!", en Bulletin of Latin American Research, 21: 2 (2002), pp. 171-190.

Brown, Matthew, "The Global History of Latin America", en Journal of Global History, 10: 3 (2015), pp. 365-386.

Brown, Timothy Scott, West Germany and the Global Sixties. The Antiauthoritarian Revolt, 1962-1978, Cambridge, Cambridge University Press, 2013.

Brown, Timothy Scott y Andrew Lison, "Introduction. The Global Sixties in Sound and Vision: Media, Counterculture, Revolt", en Brown y Lison (coords.), 2014, pp. 1-13.

Brown, Timothy Scott y Andrew Lison (coords.). The Global Sixties in Sound and Vision. Media, Counterculture, Revolt, Nueva York, Palgrave Macmillan, 2014.

Caute, David, Sixty-Eight. The Year of the Barricades, Londres, H. Hamilton, 1988.

Chaney, David, "Fragmented Culture and Subcultures", en Bennett y KahN-Harris (coords.), 2004, pp. 36-48. 
Christiansen, Samantha y Zachary A. SCARLETt, “Introduction”, en ChrisTIANSEN y SCARLETT (coords.), 2013, pp. 1-20.

Christiansen, Samantha y Zachary A. Scarlett (coords.), The Third World in the Global 1960s, Nueva York, Berghahn Books, 2013.

Claussen, Detlev, “Chiffre 68”, en Hart y Assmann (coords.), 1992, pp. 219-228.

Cooper, Frederick, "What Is the Concept of Globalization Good for? An African Historian's Perspective”, en African Affairs, 100 (2001), pp. 189-213.

Creary, Nicholas, "Speaking the Language of Protest: African Student Rebellions at the Catholic Major Seminary in Colonial Zimbabwe, 1965-1979", en Christiansen y SCARlett (coords.), 2013, pp. 116-132.

Crossley, Nick, "Protest and Lifestyle", en Fahlenbrach, Klimke y ScharLOTH (coords.), 2016, pp. 65-76.

Daniels, Robert V., Year of the Heroic Guerrilla: World Revolution and Counterrevolution in 1968, Cambridge, Harvard University Press, 1989.

DeGroot, Gerard, “The Culture of Protest: An Introductory Essay”, en DeGroot (coord.), 1998, pp. 5-11.

DeGroot, Gerard (coord.), Student Protest: The Sixties and After, Londres, Longman, 1998.

Dirlik, Arif, “The Third World”, en Fink, Gassert y Junker (coords.), 1998, pp. 295-317.

Dirlik, Arif, "Foreword: The Third World in 1968", en Christiansen y SCARLETT (coords.), 2013, pp. vii-ix.

Downs, Jim y Jennifer Manion (coords.), Taking Back the Academy! History of Activism, History as Activism, Nueva York, Routledge, 2004.

Dreyfus-Armand, Geneviève y Laurent Gervereau (coords.), Mai 68. Les mouvements étudiants en France et dans le monde, París, Bibliothèque de Documentation Internationale Contemporaine, 1988.

Dubinsky, Karen et al. (coords.), New World Coming: The Sixties and the Shaping of Global Consciousness, Toronto, Between the Lines, 2009. 
Dunn, Christopher, Brutality Garden: Tropicália and the Emergence of a Brazilian Counterculture, Chapel Hill, University of North Carolina Press, 2000.

Estrada, Álvaro, Huautla en tiempo de hippies, México, Grijalbo, 1996.

Fahlenbrach, Kathrin, Martin Klimke y Joachim Scharloth (coords.), Protest Cultures. A Companion, Nueva York, Berghahn Books, 2016.

Fink, Carole, Philipp Gassert y Detlef Junker, "Introduction”, en Fink, Gassert y JUNKER (coords.), pp. 1-27.

Fink, Carole, Philipp Gassert y Detlef Junker (coords.), 1968: The World Transformed, Cambridge, Cambridge University Press, 1998.

Foucault, Michel, Remarks on Marx. Conversations with Duccio Trombadori, Nueva York, Semiotext(e), 1991 (original publicado en italiano, 1981).

FreI, Norbert, 1968. Jugendrevolte und globaler Protest, Múnich, Deutscher Taschenbuch Verlag, 2008.

García-Robles, Jorge, El disfraz de la inocencia: la historia de Jack Keronac en México, México, Ediciones del Milenio, 2000.

Gemie, Sharif y Brian Ireland, “The Hippie Trail”, en Shatanawi y Modest (coords.), 2015, pp. 24-33.

Gilcher-Holtey, Ingrid, “France”, en Klimke y Scharloth (coords.), 2008, pp. 111-124.

Goffmann, Ken y Dan Joy, Counterculture through the Ages. From Abraham to Acid House, Nueva York, Villard Books, 2004.

Gorsuch, Anne E. y Diane P. Koenker (coords.), The Socialist Sixties. Crossing Borders in the Second World, Bloomington, Indiana University Press, 2013.

Hall, Stuart y Tony Jefrerson (coords.), Resistance through Rituals. Youth Subcultures in Post-War Britain, Londres, Routledge, 2006 (primera edición, 1993).

Hart, Dietrich y Jan Assmann (coords.), Revolution und Mythos, Fráncfort del Meno, Fischer, 1992. 
HaYton, Jeff, “'The Revolution Is Over - and We Have Won!': Alfred Hilsberg, West German Punk, and the Sixties”, en Brown y Lison (coords.), 2014, pp. $135-150$.

Hobsвawm, Eric, Age of Extremes: The Short Twentieth Century, 1914-1991, Londres, Abacus, 1995.

HoRn, Gerd-Rainer, The Spirit of '68: Rebellion in Western Europe and North America, 1956-1976, Oxford, Oxford University Press, 2007.

Howe, Stephen, Afrocentrism: Mythical Pasts and Imagined Homes, Londres, Verso, 1998.

Huq, Rupa, "Protest in the Research on Sub- and Countercultures", en Fahlenbrach, Klimke y Scharloth (coords.), 2016, pp. 33-47.

Jefferson, Tony, “Cultural Responses of the Teds”, en Hall y JefFerson (coords.), 2006, pp. 67-70.

Joвs, Richard Ivan, "Youth Movements: Travel, Protest, and Europe in 1968”, en The American Historical Review, 114: 2 (2009), pp. 376-404.

José Agustín, La contracultura en México. La historia y el significado de los rebeldes sin causa, los jipitecas, los punks y las bandas, México, Grijalbo, 1996.

Kerouac, Jack, On the Road, Nueva York, Viking Press, 1957.

Kidron, Michael y Ronald Segal, The State of the World Atlas, Londres, Heinemann, 1981.

Klimke, Martin, “West Germany”, en Klimke y Scharloth (coords.), 2008, pp. 97-110.

KLImke, Martin, The Other Alliance: Student Protest in West Germany and the United States in the Global Sixties, Princeton, Princeton University Press, 2010.

Klimke, Martin y Joachim Scharloth (coords.), 1968 in Europe. A History of Protest and Activism, 1956-1977, Basingstoke, Palgrave Macmillan, 2008.

LAfaYe, Jacques, “L’automne de Mexico (crépuscule à Tlatelolco)”, en DreyFus-Armand y Gervereau (coords.), 1988, pp. 60-65. 
Leary, Timothy, Ralph Metzner y Richard Alpert, The Psychedelic Experience; a Manual Based on the Tibetan Book of the Dead, Nueva York, University Books, 1964.

Luke, Anne, "Listening to los Beatles. Being Young in 1960s Cuba", en GORSUCH y KoEnKer (coords.), 2013, pp. 287-302.

LunN, Helen, "'Hippies, Radicals and the Sounds of Silence'. Cultural Dialectics at Two South African Universities 1966-1976", tesis de doctorado, Sudáfrica, University of Kwa-Zulu Natal, 2010.

Mabry, Donald J., The Mexican University and the State. Student Conflicts, 1910-1971, College Station, Texas A\&M University Press, 1982.

Manzano, Valeria, The Age of Youth in Argentina: Culture, Politics, and Sexuality from Perón to Videla, Chapel Hill, The University of North Carolina Press, 2014.

Markarian, Vania, "Debating Tlatelolco: Thirty Years of Public Debates about the Mexican Student Movement of 1968", en Downs y Manion (coords.), 2004, pp. 25-34.

MARKARIAN, Vania, El 68 uruguayo. El movimiento estudiantil entre molotovs y música beat, Bernal, Editorial de la Universidad Nacional de Quilmes, 2012.

Marroquín, Enrique, La contracultura como protesta. Análisis de un fenómeno juvenil, México, Joaquín Mortiz, 1975.

Marwick, Arthur, "Six Novels of the Sixties - Three French, Three Italian", en Journal of Contemporary History, $28: 4$ (1993), pp. 563-591.

Marwick, Arthur, The Sixties. Cultural Revolution in Britain, France, Italy, and the United States, c. 1958-c. 1974, Oxford, Oxford University Press, 1998.

Miles, Barry, Hippie, Nueva York, Sterling Publishing, 2004.

Monsiváis, Carlos, Amor perdido, México, Era, 1978.

Ocampo V., Tarsicio (comp.), México, conflicto estudiantil, 1968. Documentos $y$ reacciones de prensa, Cuernavaca, Centro Intercultural de Documentación, 1969. 
Pas, Nicolas, "Images d'une révolte ludique. Le muvement néerlandais Provo en France dans les années soixante”, en Revue Historique, 307: 2 (2005), pp. 343-373.

Pensado, Jaime M., Rebel Mexico: Student Unrest and Authoritarian Political Culture during the Long Sixties, Stanford, Stanford University Press, 2013.

Peter, Nicole, “Switzerland”, en Klimke y Scharloth (coords.), 2008, pp. 229-237.

Poniatowska, Elena, La noche de Tlatelolco. Testimonios de historia oral, México, Era, 1991.

Poo Hurtado, Jorge, “Los protagonistas olvidados”, en Aréchiga Robles et al., 1998, pp. 121-130.

PraTt, Mary Louise, Imperial Eyes. Travel Writing and Transculturation, Londres, Routledge, 1992.

Righart, Hans, "Moderate Versions of the 'Global Sixties': A Comparison of Great Britain and the Netherlands", en Journal of Area Studies, 6: 13 (1998), pp. 82-96.

Risch, William Jay, “Soviet 'Flower Children'. Hippies and the Youth Counter-Culture in 1970s L'viv", en Journal of Contemporary History, 40: 3 (2005), pp. 565-584.

Rodríguez KuRI, Ariel, “Los primeros días. Una explicación de los orígenes inmediatos del movimiento estudiantil de 1968", en Historia Mexicana, LIII:1 (209) (jul.-sep. 2003), pp. 179-228.

Roszak, Theodore, The Making of a Counter Culture. Reflections on the Technocratic Society and Its Youthful Opposition, Nueva York, Doubleday, 1968.

Rutherford, Scott, "Introduction. The Global Sixties", en Dubinsky et al. (coords.), 2009, pp. 1-6.

SAUL, John S., "Liberation Support and Anti-Apartheid Work as Seeds of Global Consciousness. The Birth of Solidarity with Southern African Struggles", en Dubinsky et al. (coords.), 2009, pp. 127-140. 
Shatanawi, Mirjam y Wayne Modest (coords.), The Sixties. A Worldwide Happening, Eindhoven, Lecturis, 2015.

Sherman, Daniel J. et al. (coords.), The Long 1968. Revisions and New Perspectives, Bloomington, Indiana University Press, 2013.

Sidibé, Malik, "Photo Essay”, en Shatanawi y Modest (coords.), 2015, pp. 34-41.

SloAn, Julia, "Revolution on the National Stage: Mexico, the PRI, and the Student Movement in 1968”, en Christiansen y SCARLETt (coords.), 2013, pp. 171-181.

Storey, John, "What, When, and Where are the Sixties?", en Shatanawi y Modest (coords.), 2015, pp. 10-22.

Suri, Jeremi, Power and Protest. Global Revolution in the Age of Détente, Cambridge, Mass., Harvard University Press, 2003.

SuRI, Jeremi, The Global Revolutions of 1968. A Norton Casebook in History, Nueva York, Norton, 2007.

SuRI, Jeremi, “The Rise and Fall of an International Counterculture, 19601975”, en SHERMAn et al. (coords.), 2013, pp. 93-119.

Wallerstein, Immanuel, World-Systems Analysis. An Introduction, Durham, Duke University Press, 2004.

Zolov, Eric, Refried Elvis. The Rise of the Mexican Counterculture, Berkeley, University of California Press, 1999.

ZoLov, Eric, "Mexico's Rock Counterculture (la Onda) in Historical Perspective and Memory", en Dubinsky et al. (coords.), 2009, pp. 379-486.

Zolov, Eric, "Introduction: Latin America in the Global Sixties", en The Americas, 70: 3 (2014), pp. 349-362. 